\title{
Dopant Effects on Conductivity in Copper Oxide
}

\section{Photoelectrochemical Cells}

\author{
Chia-Ying Chiang a*, Yoon Shin ${ }^{b}$, Sheryl Ehrman ${ }^{b}$ \\ a Department of Chemical Engineering, National Taiwan University of Science and Technology, \\ Taipei 106, Taiwan \\ b Department of Chemical and Biomolecular Engineering, University of Maryland, College Park, \\ Maryland 20742, USA \\ * Corresponding author. Tel: +886-2-27376641; fax: +886-2-27376641 \\ Email: cychiang@mail.ntust.edu.tw
}

\begin{abstract}
Hydrogen generation from water splitting reaction with the energy from sunlight via a photoelectrochemical (PEC) cell is one of the ultimate goals in the renewable energy field. In the PEC process, energetic excited electrons can go through fast recombination with the holes, resulting in photon energy waste and lowering the solar to hydrogen conversion efficiency. So it is essential to increase the conductivity and lower the resistance of the photoelectrodes. Here, copper oxide thin film was chosen for the demonstration of the importance for the conductivity of the film towards the photocurrent density generation. By doping with $\mathrm{Li}, \mathrm{Ni}, \mathrm{Co}, \mathrm{Ag}, \mathrm{Zn}$ and $\mathrm{Mg}$, the conductivity of the films increases from $3 \times 10^{-6} \mathrm{~S} / \mathrm{cm}$ for the intrinsic $\mathrm{CuO}$ film to up to $10^{-4} \mathrm{~S} / \mathrm{cm}$, two orders of magnitude higher, and thus leading to up to four folds increase in photocurrent density. On the other hand, the addition of $\mathrm{Cr}, \mathrm{Fe}$, and $\mathrm{Mn}$ introduced into $\mathrm{CuO}$ film leads to lower conductivity, to $10^{-8} \sim 10^{-9} \mathrm{~S} / \mathrm{cm}$, and leads to a significant decrease of the photocurrent density. A correlation between the photocurrent density and conductivity is also reported in this study.
\end{abstract}

Key words: dopants; copper oxide; photoelectrochemical cell; water splitting 


\section{Introduction}

Lowering mankind's carbon footprint is the one of the ultimate goals of renewable energy research. Among various renewable energies, hydrogen generation from water splitting reaction with the energy from sun via a photoelectrochemical (PEC) cell is one of the cleanest processes for electricity generation, with an almost near zero carbon footprint [1-3]. The very first step in a water splitting PEC cell is, as its order of the name, photo-electro-chemical cell, light absorption. The sunlight, i.e. photon, is absorbed by the semiconductor electrode material and this leads to the excitation of electrons from the valence bands to conduction bands, the second part of a PEC cell. The excited high energy electrons then transfer to the electrode and electrolyte (water) interface for triggering the redox chemical reaction, i.e. converting water into hydrogen and oxygen (the third part of a PEC cell). In order to absorb a significant fraction of incident photons, a semiconductor material with low band gap is favorable. However, in order to conquer the over potential of the water splitting reaction, usually a material with band gap larger than $1.6 \mathrm{eV}$ is preferred. As a result, copper oxide, $\mathrm{CuO}$, a p-type semiconductor, has been shown to have a bandgap around 1.4-1.8 eV [4-8] and a suitable band position for the water reduction reaction (from $\mathrm{H}^{+}$to $\mathrm{H}_{2}$ ).

In the PEC process, energetic excited electrons can recombine with the holes, resulting in the photon energy waste and lowering solar to hydrogen conversion efficiency. A system with fast electron transfer can as a result in a significant increase in the system' s efficiency. In copper oxide PEC cells, however, due to the relatively high resistance of $\mathrm{CuO}$, most of the photon-excited electrons might not have the chance to 
move to the electrode and electrolyte interface for reaction. So, it is essential to increase the conductivity and lower the resistance of the copper oxide photocathode. In our previous study, a detailed Li doped $\mathrm{CuO}$ photoelectrochemical cell study was conducted [6]. However, due to the cost and abundance of the material, there might be some other compatible candidates. So in order to provide more possibilities for the dopant selection, in this study, a series of atoms are doped into copper oxide to increase the conductivity. Usually, if the difference in ionic radii is larger than $15 \%$, then the alien atoms might not be easily incorporated into the copper oxide crystal lattice [10]. Based on this criteria, along with the earth abundance merit, eight dopants were targeted in this study. In order to form a uniform copper oxide phase (the dopants are soluble in copper oxide) and reduce the chance for phase segregation, a fast particle formation and quenching process, namely flame spray pyrolysis (FSP), is chosen. FSP is a flame-assisted liquid droplet-vapor-to-particle conversion process and it can be used to produce fine and pure particles in the as-prepared state in just few miliseconds [9]. A correlation between the conductivity and PEC efficiency in terms of photocurrent density based on six $3 \mathrm{~d}$ and one $4 \mathrm{~d}$ orbital transition metals and an alkaline earth metal, $\mathrm{Mg}$, is also demonstrated.

\section{Experimental}

\subsection{Doped Copper Oxide Photocathodes Preparation}

Flame spray pyrolysis (FSP) was chosen as a fast nanoparticle formation process. $1 \mathrm{M}$ copper nitrate $\left[\mathrm{Cu}\left(\mathrm{NO}_{3}\right)_{2} \cdot 3 \mathrm{H}_{2} \mathrm{O}\right]$ (Strem Chemicals Inc., USA) solution was fed into the flame spray pyrolysis system along with the different concentrated dopant solution, i.e. 0.5 at $\%$ and 2 at $\%$, to form the doped copper 
oxide nanoparticles. Precursors for magnesium $(\mathrm{Mg})$, chromium $(\mathrm{Cr})$, manganese $(\mathrm{Mn})$, iron $(\mathrm{Fe})$, cobalt $(\mathrm{Co})$, zinc $(\mathrm{Zn})$, and silver $(\mathrm{Ag})$ were from the nitrates or acetates solution except nickel chloride precursor for Ni dopant. Metal nitrates were used as precursor for dopants $\mathrm{Fe}, \mathrm{Mg}, \mathrm{Zn}, \mathrm{Co}, \mathrm{Ag}, \mathrm{Cr}$ and metal acetate was used for dopant Mn, (Strem chemicals Inc USA). All the chemicals are reagent grade. The nanoparticles were formed by the decomposition of precursor in a methane flame with adiabatic temperature of $2185 \mathrm{~K}$ and the highest measured temperature of $1748 \mathrm{~K}$ by a thermocouple with correction of the radiative heat losses from the thermocouple. Particles were collected on a filter paper (W. L. Gore \& Associated Inc., USA) by a vacuum pump. A more detailed description of the experimental setup can be found in our previous study [9]. Ethanol was used to suspend these nanoparticles at the particle to solvent ratio of $30 \mathrm{mg} / \mathrm{mL}$ and ultrasonication was applied to decrease the particle aggregation. The slurry was formed into a thin film (thickness ca. $850 \mathrm{~nm}$ ) on conduction indium-tin-oxide coated microscope slides (SPI supplies, USA) by using spin coating process (Headway PWM32 Spinner, USA) with the rotation speed of $2000 \mathrm{rpm}$ for 8 sec. The film was then sintered in a muffle furnace (Thermo Scientific Thermolyne, USA) at $450{ }^{\circ} \mathrm{C}$ for $1 \mathrm{hr}$.

\subsection{Characterization}

The surface chemical composition of the doped $\mathrm{CuO}$ samples were determined using a Kratos Axis 165 X-ray photoelectron spectrometer operating in hybrid mode using $\mathrm{Al} \mathrm{K \alpha}$ monochromatic X-rays (1486.6 eV). The survey spectra were done under a pass energy of $160 \mathrm{eV}$ while the high resolution spectra were done under a pass energy of $20 \mathrm{eV}$. Charge neutralization was 
required to minimize surface charge. For crystal components study, XRD chemical component analysis was conducted with a Philips PW 1800 diffractometer coupling with a graphite monochromator with an incident radiation of $\mathrm{Cu} \mathrm{K} \alpha(\lambda=1.54 \AA)$. The photoelectrochemical study was conducted in $1 \mathrm{M} \mathrm{KOH} \mathrm{(pH} \mathrm{14)} \mathrm{electrolyte} \mathrm{under} \mathrm{a} \mathrm{three-electrode} \mathrm{configuration} \mathrm{where}$ $\mathrm{Ag} / \mathrm{AgCl}$ in saturated $\mathrm{KCl}$ (Gamry Instruments, USA) and platinum gauze (52 mesh, 99.9\%, Sigma-Aldrich, USA) were used as reference electrode and counter electrode, respectively. The light source was a $150 \mathrm{~W}$ full spectrum solar simulator (Oriel Instruments, USA) with a full reflector bean turning mirror (Oriel Instruments, USA) and a AM1.5G filter with a measured intensity of 1 sun $\left(1000 \mathrm{~W} / \mathrm{m}^{2}\right)$ by a reference cell (Oriel instrument, USA) at $25{ }^{\circ} \mathrm{C}$. For the film conductivity measurement, gold was sputtered at two ends of the $\mathrm{CuO}$ film which was coated on quartz substrate as electrode. The distance between two ends was $1.5 \mathrm{~cm}$. The electrical conductivity of the films was determined multiple times by electrochemical impedance spectroscopy (EIS) carried out on a potentiostat/galvanostat (Solartron, USA).

\section{Results and Discussion}

In this study, eight different dopants were selected due to their similar size of the ionic radii to $\mathrm{Cu}^{2+}(87 \mathrm{pm})$. The dopants includes alkaline earth metal $\mathrm{Mg}$, 3d transition metals such as $\mathrm{Cr}, \mathrm{Mn}, \mathrm{Fe}, \mathrm{Co}, \mathrm{Ni}, \mathrm{Zn}$ and $4 \mathrm{~d}$ transition metal Ag. Usually, if the difference in ionic radii is larger than $15 \%$, then the alien atoms might not be easily incorporated into the copper oxide crystal lattice [10]. Based on the XRD for the crystalline analysis for flame spray pyrolysis made 2 at $\%$ doped $\mathrm{CuO}$ nanoparticles, only the monoclinic $\mathrm{CuO}$ phase was found in all 
samples as shown in Figure 1. This suggests the alien atoms were doped into the lattice rather then form a second phase. Moreover, there is no obvious crystal orientation change with dopant introduced. The crystalline size for these particles was estimated to be around $30 \mathrm{~nm}$ based on the Scherrer equation. The SEM for the morphology of the as-prepared copper oxide film is shown in Figure 2. Furthermore, in order to know the chemical composition of the doped $\mathrm{CuO}$ films, XPS analysis was conducted and the result is given in Table 1 . The dopant concentrations for $\mathrm{Mg}, \mathrm{Cr}, \mathrm{Mn}, \mathrm{Ni}$ and $\mathrm{Zn}$ at the surface are $12.1 \mathrm{at} \%, 7.12$ at\%, 60.8 at $\%, 2.90$ at\%, and 8.33 at\% respectively, and these dopant concentrations are relatively higher then in the bulk where the precursor dopant concentration is set to be 2 at\%. This might be explained by the surface segregation of these dopants. In contrast, there is no observable amount of $\mathrm{Fe}$ in the $\mathrm{CuO}$ film surface and only 1.89 at\% and 0.417 at $\%$ for Co and Ag was found, respectively. The valence and the corresponded ionic radii of these atoms were also tabulated in Table 1. The $\mathrm{Cu}^{2+}$ ion has ionic radius of $87 \mathrm{pm}$. For example, $\mathrm{Li}$ and $\mathrm{Ag}$ exist as $1+$ while $\mathrm{Mg}, \mathrm{Ni}$, and $\mathrm{Zn}$ are $2+$. Co can be either in $2+$ or $3+$. However, due to the overlap of the characteristic peaks in the spectra, the valence for $\mathrm{Cr}, \mathrm{Mn}$ and $\mathrm{Fe}$ are hard to determine.

The photocurrent density at corresponding applied voltage for various dopants added into $\mathrm{CuO}$ with concentration of both 2 at $\%$ and 0.5 at $\%$ is shown in Figure 3. The experiment was carried in $\mathrm{pH} 14 \mathrm{KOH}$ solution with a three-electrode system under AM1.5G spectrum at 1 sun irradiation. The applied voltage was set to scan from $0.2 \mathrm{~V}$ to $-0.7 \mathrm{~V}$ vs $\mathrm{Ag} / \mathrm{AgCl}$ in saturate $\mathrm{KCl}$ solution. In addition to the dopants in this study, the result of 2 at\% $\mathrm{Li}$ doped $\mathrm{CuO}$ from Chiang et al. [6], is also included for the comparison. In Fig 3(a), among these 2 at\% experimental result, "dark" 
represents that there is no incident light on the sample, and others are with 1 sun irradiance. It can be seen that $\mathrm{Li}$ doped sample shows the best performance in terms of photocurrent density generated by the incident light. This is because there is two orders of magnitude increase in conductivity, i.e. $3 \times 10^{-6} \mathrm{~S} / \mathrm{cm}$ for intrinsic $\mathrm{CuO}$ film and $1 \times 10^{-4} \mathrm{~S} / \mathrm{cm}$ for 2 at $\% \mathrm{Li}$ doped $\mathrm{CuO}$ film, for decreasing the resistance of generated charge carriers' transfer [6]. $\mathrm{Ni}, \mathrm{Co}, \mathrm{Ag}, \mathrm{Zn}$ and $\mathrm{Mg}$ are following after $\mathrm{Li}$ with the relatively high photocurrent density. These metal ions not only have sizes similar to $\mathrm{Cu}^{2+}$ ions which make them more easily incorporated into the $\mathrm{CuO}$ lattice but also their incorporation results in a dramatic increase in the conductivity of the $\mathrm{CuO}$ as tabulated in Table 1. For example, in our previous study [6], the electrical conductivity of intrinsic $\mathrm{CuO}$ film prepared by spin coating is ca. $3 \times 10^{-6} \mathrm{~S} / \mathrm{cm}$ and for these dopants with positive effect on photocurrent density, i.e. Ni, Co, Ag, Zn, and $\mathrm{Mg}$, the electrical conductivity is found to be higher and ranging from $4.4 \times 10^{-6}$ to $1.8 \times 10^{-5} \mathrm{~S} / \mathrm{cm}$. In contrast, dopants like $\mathrm{Cr}, \mathrm{Mn}$, and Fe lower the conductivity to ca. $10^{-8} \sim 10^{-9} \mathrm{~S} / \mathrm{cm}$ and thus decrease the photocurrent density. So far, it is noticed that the conductivity has an important effect on the PEC efficiency. Also, in Figure 3(b), similar to the 2 at $\%$ doped $\mathrm{CuO}$ samples, a set of 0.5 at\% doped $\mathrm{CuO}$ films show the same trend, i.e. $\mathrm{Ni}$ and $\mathrm{Ag}$ have a positive effect on the photocurrent density while $\mathrm{Cr}$, Mn and Fe show a negative effect.

Furthermore, an interesting finding during a more detailed analysis between the relation of the conductivity and photocurrent density of the film is shown in Figure 4, photocurrent density vs. conductivity of the film. In the figure, the photocurrent density is based on the applied voltage of $-0.55 \mathrm{~V}$ vs. $\mathrm{Ag} / \mathrm{AgCl}$ with 1 sun $\mathrm{AM} 1.5 \mathrm{G}$ irradiance and the data point shown in red represents the intrinsic $\mathrm{CuO}$ film photocathode. Meanwhile, the result of 2 at $\%$ and 0.5 at $\%$ doped $\mathrm{CuO}$ film 
photocathodes are also included. Fitting these results, a correlation between the photocurrent density and conductivity of the film electrode is found to be $y=$ $11.48 x^{0.2478}$ where $\mathrm{y}$ is the photocurrent density and $\mathrm{x}$ is the conductivity, over a range of conductivity ca. $10^{-9} \sim 10^{-4} \mathrm{~S} / \mathrm{cm}$ and and a photocurrent density range of ca. $0.1 \sim 1.5 \mathrm{~mA} / \mathrm{cm}^{2}$. As the conductivity increases approximately an order of magnitude, the photocurrent density almost doubles. Similarly, as the conductivity decreases for about an order, the photocurrent density becomes about half (1/1.8 times). A linear plot (insert in the figure) is also given in Figure 4. As the conductivity keeps increasing, the photocurrent density does not show the linear increase instead an obvious leveled trend is observed. This is because once the conductivity reaches a certain level when the PEC efficiency is no longer limited by conductivity, likely, surface morphology plays a more important role since the water splitting reaction takes place at the interface of electrode and electrolyte. If there is not enough surface area for those photon generated electrons to react with water, then no matter how conductive the cell is, the efficiency will not be high. Furthermore, among these dopants, Ni and Co have extremely positive effects on the PEC water splitting reaction, and they are good catalysts for electrocatalytic water splitting as well [11]. Moreover, comparing to $\mathrm{Cu}$ with positive $\mathrm{H}^{+}$binding energy, upon addition of $\mathrm{Ni}$ and Co with negative $\mathrm{H}^{+}$binding energy [11], the material might easily have reactants absorb on the surface and have the products leave the surface, thus leading to a higher water splitting efficiency.

\section{Conclusion}

As dopants were introduced into $\mathrm{CuO}$ for photoelectrochemical cell, the apparent effects on photocurrent density were observed. By doping with $\mathrm{Li}, \mathrm{Ni}$, 
$\mathrm{Co}, \mathrm{Ag}, \mathrm{Zn}$ and $\mathrm{Mg}$, the conductivities of the $\mathrm{CuO}$ films increase from $3 \times 10^{-6} \mathrm{~S} / \mathrm{cm}$ for the intrinsic $\mathrm{CuO}$ film to $10^{-4} \mathrm{~S} / \mathrm{cm}$ for doped $\mathrm{CuO}$ films and that is about two orders of magnitude higher, and thus leading to a few percent to four folds increase in photocurrent density. Meanwhile, the addition of $\mathrm{Cr}, \mathrm{Fe}$, and $\mathrm{Mn}$ introduced into $\mathrm{CuO}$ film leads to lower the conductivity to $10^{-8} \sim 10^{-9} \mathrm{~S} / \mathrm{cm}$. As a result, a much lower photocurrent density was observed. A correlation between photocurrent density and conductivity of the film is obtained based on these nine different dopants in $\mathrm{CuO}$ films along with the intrinsic $\mathrm{CuO}$ film. The photocurrent density increases at the rate of 1.8 times when the conductivity of the film increases a by a factor of 10 .

\section{Acknowledgements}

Authors acknowledge support from US National Science Foundation DMR 0806610 and from the NSC 102-2218-E-011-019-MY2, National Science Council (NSC) of Taiwan.

\section{References}

[1] Veziroglou TN. Dawn of the hydrogen age. Int J Hydrogen Energ 1998; 23: $1077-1978$.

[2] Veziroglou TN Quarter century of hydrogen movement 1974-2000. Int J Hydrogen Energ 2000; 25: 1143-50.

[3] Bak T, Nowotny J, Rekas M, Sorrell CC. Photo-electrochemical hydrogen generation from water using solar energy. Materials-related aspects. Int J Hydrogen Energ 2002; 27: 991-1022. 
[4] Chiang CY, Chang MH, Liu HS, Tai CY, Ehrman S. Process Intensification in The Production of Photocatalysts for Solar Hydrogen Generation. Ind Eng Chem Res 2012; 51: 5207-15.

[5] Chiang CY, Shin Y, Aroh K, Ehrman S. Copper Oxide Photocathodes Prepared by a Solution Based Process. Int J Hydrogen Energ 2012; 37: 8232-39.

[6] Chiang CY, Shin Y, Ehrman S. Li Doped CuO Film Electrodes for Photoelectrochemical Cells. J Electrochem Soc 2012; 159: B227-31.

[7] Chiang CY, Aroh K, Ehrman S. "Copper Oxide Nanoparticle Made by Flame Spray Pyrolysis for Photoelectrochemical Water Splitting - Part I. CuO Nanoparticle Preparation.” Int. J. Hydrogen Energ, 2012, 37, 4871-4879.

[8] Chiang CY, Aroh K, Franson N, Satsang VR, Dass S, Ehrman S. Copper Oxide Nanoparticle Made by Flame Spray Pyrolysis for Photoelectrochemical Water Splitting - Part II. Photoelectrochemical Study. Int J Hydrogen Energ 2011; 36: $15519-26$.

[9] Chiang CY, Aroh K, Ehrman S. Copper Oxide Nanoparticle Made by Flame Spray Pyrolysis for Photoelectrochemical Water Splitting - Part I. CuO Nanoparticle Preparation. Int J Hydrogen Energ 2012; 37: 4771-79

[10] Bradley D. Fahlman, Materials Chemistry, $2^{\text {nd }}$ edition, Springer, p. 78.

[11] Jaramillo TF, Jørgensen KP, Bonde J, Nielsen JH, Horch S, Chorkendorff I. Identification of Active Edge Sites for Electrochemical $\mathrm{H}_{2}$ Evolution from $\mathrm{MoS}_{2}$ Nanocatalysts. Science 2007; 317: 100-2. 


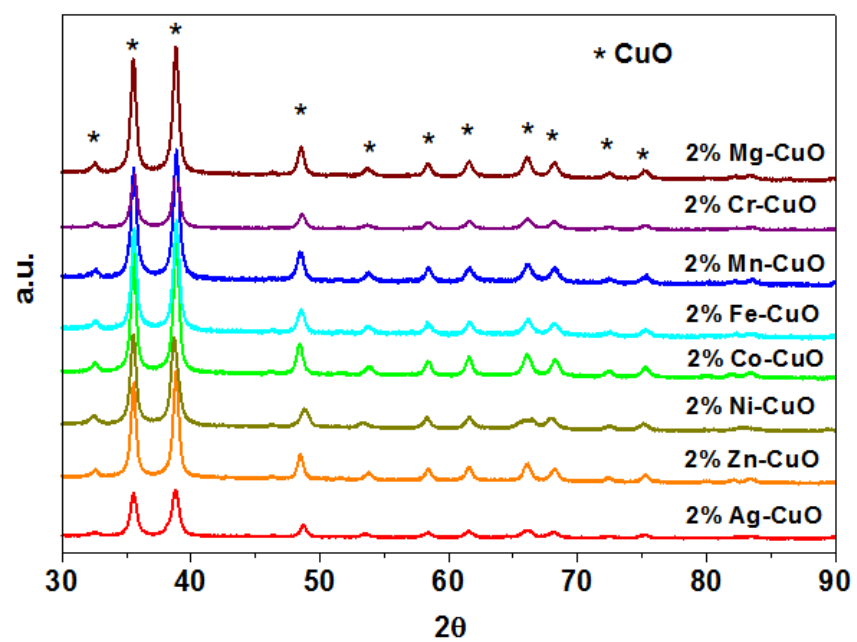

Fig. 1. XRD for 2 at $\%$ doped-CuO photocathodes prepared by flame spray pyrolysis and spin coating process in this study. 


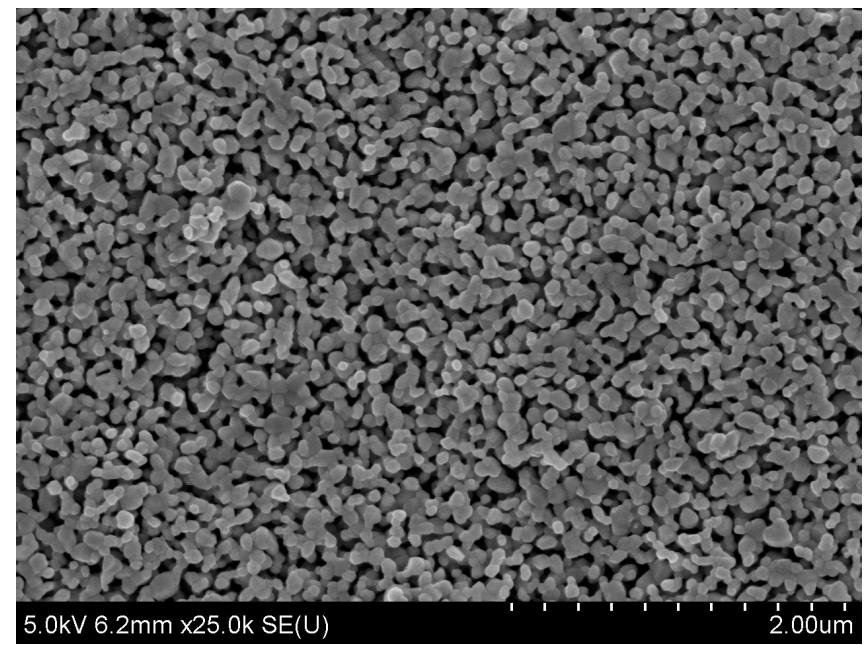

Figure 2. SEM image of the surface morphology for the as-prepared copper oxide film electrode. 
(a)

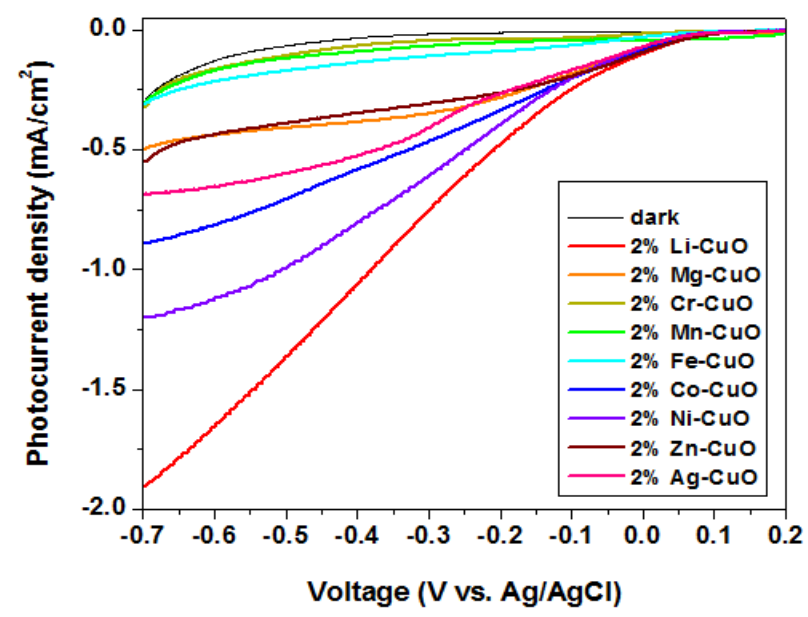

(b)

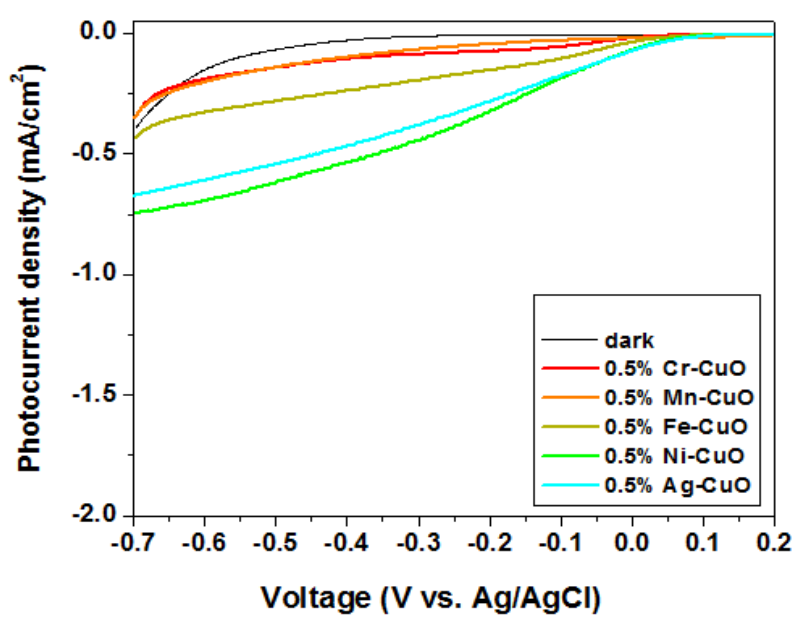

Fig. 3. Photocurrent density vs. applied voltage for doped $\mathrm{CuO}$ photocathodes at different bias voltage applied: (a) 2 at $\%$ doped $\mathrm{CuO}$ in this study as well as the 2 at $\%$ Li doped $\mathrm{CuO}$ in the literature [6] and (b) 0.5 at $\%$ dopants added. 


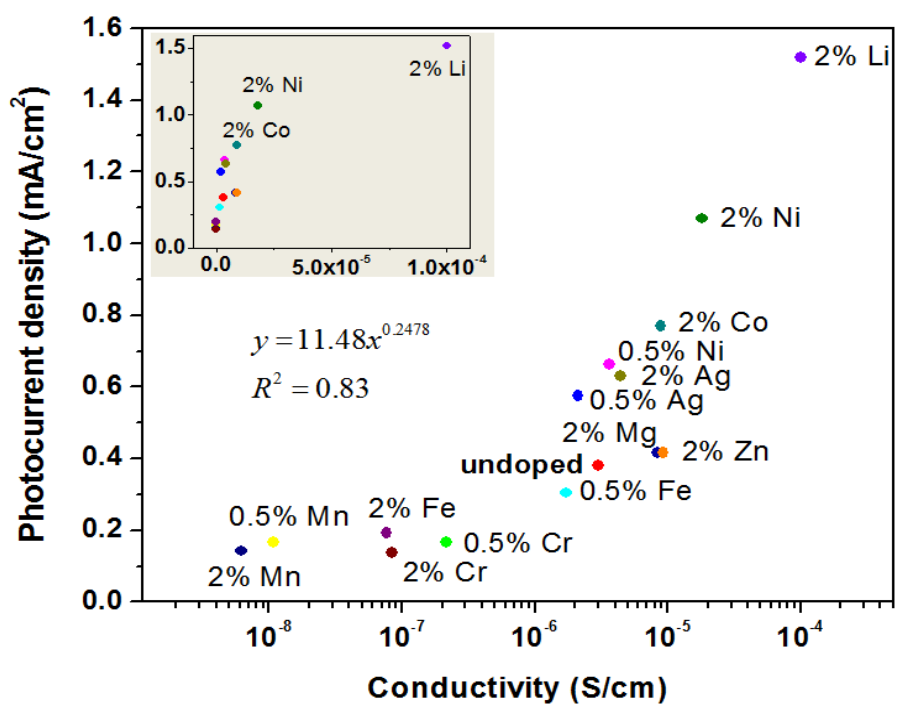

Fig. 4. Photocurrent density vs conductivity of the doped $\mathrm{CuO}$ photocathodes. 
Table 1.2 at $\%$ doped $\mathrm{CuO}$ film (thickness ca. $850 \mathrm{~nm}$ ) photoelectrode properties: doping concentration at surface by XPS, ionic radii, conductivity and photocurrent density at bias voltage of $-0.55 \mathrm{~V}$ vs. $\mathrm{Ag} / \mathrm{AgCl}$. (* Intrinsic $\mathrm{CuO}$ film; ** can't be determined due to the peaks overlap)

\begin{tabular}{|c|c|c|c|c|}
\hline Dopant & $\begin{array}{c}\text { Dopant } \\
\text { concentration as } \\
\text { in film (at \%) }\end{array}$ & $\begin{array}{l}\text { Ionic radii } \\
\text { (picometers) } \\
\text { and valence }\end{array}$ & $\begin{array}{l}\text { Conductivity } \\
(\mathrm{S} / \mathrm{cm})\end{array}$ & $\begin{array}{c}\text { Photocurrent density } \\
\left(\mathrm{mA} / \mathrm{cm}^{2}\right) \text { at }-0.55 \mathrm{~V} \\
\text { vs. } \mathrm{Ag} / \mathrm{AgCl}\end{array}$ \\
\hline$---*[6]$ & --- & 87 for $\mathrm{Cu}^{2+}$ & $2 \times 10^{-6} \sim 4 \times 10^{-6}$ & 0.35 \\
\hline $\mathrm{Li}[6]$ & 3.6 & $90(1+)$ & $1.00 \times 10^{-4}$ & 1.52 \\
\hline $\mathrm{Mg}$ & 12.1 & $86(2+)$ & $8.43 \times 10^{-6}$ & 0.417 \\
\hline $\mathrm{Cr}$ & 7.12 & $---* *$ & $8.33 \times 10^{-8}$ & 0.138 \\
\hline $\mathrm{Mn}$ & 60.8 & --- ** & $6.19 \times 10^{-9}$ & 0.142 \\
\hline $\mathrm{Fe}$ & 0 & $---* *$ & $7.63 \times 10^{-8}$ & 0.192 \\
\hline $\mathrm{Co}$ & 1.89 & $\begin{array}{l}79(2+) \text { or } \\
68.5(3+) \\
\end{array}$ & $8.88 \times 10^{-6}$ & 0.77 \\
\hline $\mathrm{Ni}$ & 2.90 & $83(2+)$ & $1.80 \times 10^{-5}$ & 1.07 \\
\hline $\mathrm{Zn}$ & 8.33 & $88(2+)$ & $9.22 \times 10^{-6}$ & 0.417 \\
\hline $\mathrm{Ag}$ & 0.417 & $129(1+)$ & $4.43 \times 10^{-6}$ & 0.63 \\
\hline
\end{tabular}

